\title{
Microreview
}

\section{Nods, Nalps and Naip: intracellular regulators of bacterial-induced inflammation}

\author{
Mathias Chamaillard, ${ }^{1}$ Stephen E. Girardin, ${ }^{2}$ \\ Jérôme Viala ${ }^{3}$ and Dana J. Philpott ${ }^{3 *}$ \\ ${ }^{1}$ Department of Pathology, University of Michigan Medical \\ School, Ann Arbor, Michigan, USA. \\ ${ }^{2}$ Pathogénie Microbienne Moléculaire and \\ ${ }^{3}$ Immunité Innée et Signalisation, Institut Pasteur, 28 rue \\ du Dr Roux, 75724 Paris, France.
}

\section{Summary}

The innate immune system is the most ancestral and ubiquitous system of defence against microbial infection. The microbial sensing proteins involved in innate immunity recognize conserved and often structural components of microorganisms. One class of these pattern-recognition molecules, the Toll-like receptors (TLRs), are involved in detection of microbes in the extracellular compartment whereas a newly discovered family of proteins, the NBS-LRR proteins (for nucleotide-binding site and leucine-rich repeat), are involved in intracellular recognition of microbes and their products. NBS-LRR proteins are characterized by three structural domains: a C-terminal leucine-rich repeat (LRR) domain able to sense a microbial motif, an intermediary nucleotide binding site (NBS) essential for the oligomerization of the molecule that is necessary for the signal transduction induced by different $\mathrm{N}$-terminal effector motifs, such as a pyrin domain (PYD), a caspase-activating and recruitment domain (CARD) or a baculovirus inhibitor of apoptosis protein repeat (BIR) domain. Two of these family members, Nod1 and Nod2, play a role in the regulation of pro-inflammatory pathways through NF-KB induced by bacterial ligands. Recently, it was shown that Nod2 recognizes a specific peptidoglycan motif from bacteria, muramyl dipeptide (MDP). A surprising number of human genetic disorders have been linked to NBSLRR proteins. For example, mutations in Nod2, which

Received 8 April, 2003; revised 22 May, 2003; accepted 22 May, 2003. *For correspondence. E-mail philpott@pasteur.fr; Tel. (+33) 1456889 93; Fax (+33) 140613902.

(C) 2003 Blackwell Publishing Ltd render the molecule insensitive to MDP and unable to induce NF-KB activation when stimulated, are associated with susceptibility to a chronic intestinal inflammatory disorder, Crohn's disease. Conversely, mutations in the NBS region of Nod2 induce a constitutive activation of NF-кB and are responsible for Blau syndrome, another auto-inflammatory disease. Nalp3, which is an NBS-LRR protein with an N-terminal Pyrin domain, is also implicated in rare auto-inflammatory disorders. In conclusion, NBS-LRR molecules appear as a new family of intracellular receptors of innate immunity able to detect specific bacterial compounds and induce inflammatory response; the dysregulation of these processes due to mutations in the genes encoding these proteins is involved in numerous auto-inflammatory disorders.

\section{Introduction}

All animals and plants possess a means of innate defence against microbial attack. In most organisms, this system represents the sole mechanism for protection against infection; only vertebrates possess in addition to this, an adaptive immune system for selective protection against specific microbes. Innate immune systems of both plants and animals rely on surveillance proteins to recognize microbes that interact with the host cell. Strikingly, the microbial recognition proteins of such diverse hosts share common protein signatures implying evolutionary conservation of these systems for disease resistance (Girardin et al., 2002; Inohara et al., 2001). The recognition molecules involved in host defence possess a microbial-ligand sensing domain, which is often made up of a series of leucine-rich repeat (LRR) units, and a protein-protein interaction domain that links microbial recognition to signal transduction pathways to initiate the defensive response. We make a distinction at this point of stating ligand 'sensing' rather than ligand 'binding', as only in a few cases has direct interaction between the microbial ligand and recognition molecule been demonstrated. Thus, we will use the term 'pattern-recognition molecules' or PRMs for these microbe sensing proteins to distinguish them from bona fide receptors. On the side of the microbe, 
the factors that are recognized by PRMs are normally structural components of the microbe like lipopolysaccharide (LPS) or other components of the cell wall. These components are termed 'pathogen-associated molecular patterns' or PAMPs because they are, by and large, conserved among diverse sets of microorganisms (Medzhitov and Janeway, 1998).

Pattern-recognition molecules either present their ligand sensing domains extracellularly or intracellularly. In mammals, the Toll-like receptor (TLR) family represents membrane-bound PRMs that detect PAMPs in the extracellular environment (Barton and Medzhitov 2002). More recently, a family of intracellular proteins has been discovered that likely represents a means of cytosolic surveillance; these intracellular PRMs mediate host defence by detecting PAMPs that are presented to the cytosolic compartment (Philpott et al., 2001; Inohara et al., 2002; Tschopp et al., 2003). This class of PRMs includes the Nod (for nucleotide-binding oligomerization domain) and Nalp (for NACHT, LRR and PYD domains; see below) proteins, which possess a central nucleotide-binding site (NBS) and a C-terminal LRR domain, thus classifying them into a new family of proteins termed NBS-LRR (see below). This review will focus primarily on a few of these family members and the role of these intracellular PRMs in host defence and human disease. For more details on TLRs as well as the NBS-LRR family in general, we direct the reader to the following excellent reviews on this subject (Medzhitov and Janeway, 1998; Schuster and Nelson 2000; Girardin et al., 2002; Medzhitov 2001; Harton et al., 2002; Inohara et al., 2002; Tschopp et al., 2003; Inohara and Nuñez 2003).

\section{The NBS-LRR family of proteins}

The NBS-LRR family of proteins was recently identified and the role of these intracellular proteins in host defence is beginning to be elucidated. The defining feature of the NBS-LRR family of cytoplasmic proteins is a tripartite domain structure with a C-terminal LRR domain, a central NBS domain or NACHT (for neuronal apoptosis inhibitor protein, CIITA, HET-E and TP1) and at the Nterminus, a protein-protein interaction domain, CARD (caspase-activating and recruitment domain), PYD (pyrin domain), or BIR (baculovirus inhibitor of apoptosis protein repeat; Girardin et al., 2002; Inohara et al., 2002; Inohara and Nuñez, 2003; Tschopp et al., 2003). This family has also been termed 'CATERPILLER', which is an acronym for CARD, transcription enhancer, R- (purine-) binding, pyrin, lots of LRRs (Harton et al., 2002). The presence of these different $\mathrm{N}$-terminal domains divides these proteins into subfamilies, for example, Nalps contain PYD, Nods possess CARD domains and NAIP (for neuronal apoptosis inhibitor) have BIR domains (see
Fig. 1). In terms of domain structure, these proteins resemble disease resistance proteins in plants, which first led to the speculation that they may play similar roles in defence against microbes in mammalian cells (Girardin et al., 2002).

In both plant $R$ proteins and in TLRs, the LRR domain is involved in ligand sensing suggesting that is also likely the case for NBS-LRR proteins (Staskawicz et al., 2001). Furthermore, deletion of the LRR domain of Nod1 or Nod2 renders these molecules insensitive to their bacterial ligands (Inohara et al., 2001). This domain in the NBS-LRR family is predicted to form a non-globular horse-shoe configuration based on the crystal structure of a prototypical protein possessing this domain, the porcine and human ribonuclease inhibitors (Kobe and Deisenhofer, 1993; Kajava and Kobe 2002). Proteins that possess LRRs are implicated in the interaction with a great diversity of ligands, demonstrating the binding versatility of this structural motif (Kobe and Deisenhofer, 1994).

The NBS domain contains a number of distinct motifs including the Walker A and Walker B motifs, which are the ATP/GTPase-specific $P$ loop and the $\mathrm{Mg}^{2+}$ binding site respectively. This domain mediates oligomerization of NBS-LRR proteins and is predicted to bind ATP, except for CIITA, which binds GTP (Tschopp et al., 2003). Comprehensive mutational analyses of CIITA, have revealed that the nucleotide binding domain is essential for the oligomerization of the molecule and its subsequent transactivation capacity (Linhoff et al., 2001). By comparison, it is likely that this domain in other NBS-LRR proteins would bind nucleotides that would then regulate the activity of the molecule.

The N-terminal PYD and CARD domains of the NBSLRR proteins mediate homophilic interactions between other molecules carrying these motifs. Both PYD and CARD are members of the death domain-fold superfamily that also includes death domains and death effector domains. Members of this family are involved in apoptosis and/or inflammation (Hofmann et al., 1997; Bertin and DiStefano 2000). CARD domains are found in a number of pro-apoptotic proteins like caspase 1 and caspase 9. In the case of Nod1 and Nod2, this domain mediates the activation of a pro-inflammatory cascade through its interaction with the CARD domain of Rip2 (for receptor-interacting protein 2; also known as RICK and CARDIAK), a protein capable of activating NF-KB (Bertin et al., 1999; Inohara et al., 1999; Girardin et al., 2001). The PYD domain is also implicated in proinflammatory processes. This domain was first described in Pyrin, a protein whose gene is mutated in patients that suffer from a hereditary disorder called familial Mediterranean fever (Martinon et al., 2001; Bertin and DiStefano 2000). 


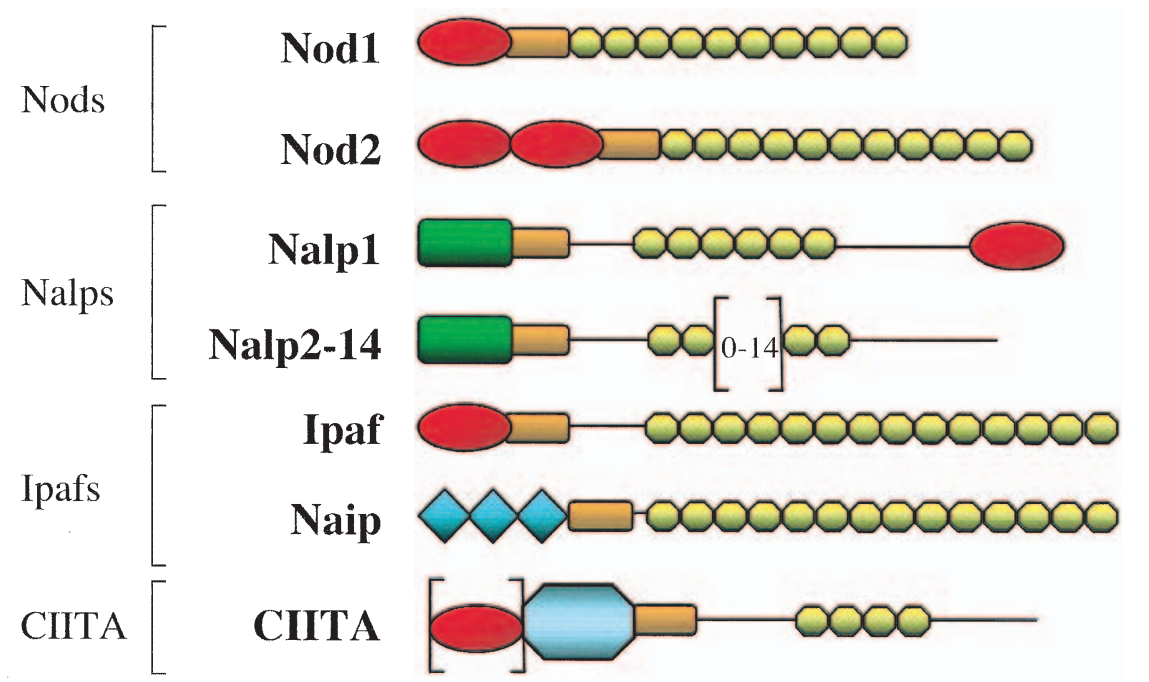

Fig. 1. NBS-LRR family of proteins. Domain structures are shown for the subfamilies of NBS-LRR proteins, Nods, Nalps, Ipafs and CIITA. For CIITA, brackets are shown around the CARD domain as this domain is found in a subtype of CIITA molecules expressed in dendritic cells (Nickerson et al., 2001). CARD, caspase-activating and recruitment domain; NBS, nucleotide binding site; LRR, leucine-rich repeat; PYD, pyrin domain; BIR, baculovirus inhibitor of apoptosis protein repeat; $A D$, activation domain; Nod, nucleotide-binding oligomerization domain; Nalp, NACHT (for neuronal apoptosis inhibitor protein, CIITA, HET-E and TP1)-, LRR- and PYD; Ipaf, ICE (interleukin-1 converting enzyme) protease activating factor; Naip, neuronal inhibitor of apoptosis; CIITA, class II transcriptional activator (after Tschopp et al., 2003).

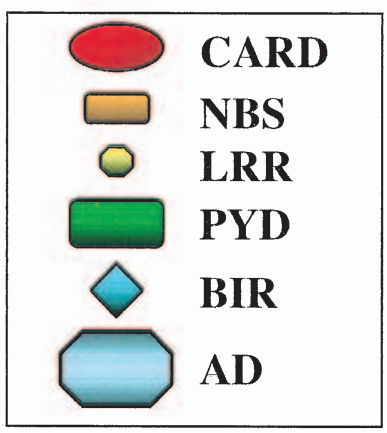

\section{Nod1}

Using a genomic database mining approach to search for Apaf-1 homologues, Inohara et al. (1999) and Bertin et al. (1999) discovered Nod1/CARD4. Similar to Apaf-1, Nod1 has a N-terminal CARD domain and central NBS/NACHT, but instead of the WD repeats found in Apaf-1, Nod1 has an LRR domain. Biochemical investigation into the signalling pathways induced downstream of Nod1 demonstrated that Nod1 oligomerization is sufficient to induce the recruitment of Rip2 through homophilic CARD-CARD interaction (Inohara et al., 1999; Bertin et al., 1999). Rip2 is an adapter protein sharing homology with IRAK, RIP proteins (involved in signalling pathways downstream of TLRs and the TNF $\alpha$ receptor) and plant Pto kinases (McCarthy et al., 1998). Subsequently, the interaction between Nod1 and Rip2 leads to the activation of the NF$\kappa B$ pathway through the recruitment of the IKK complex to the central domain of Rip2 (Inohara et al., 2000). Alternatively, it has been proposed that Nod1 could enhance Caspase-1 function also through CARD-CARD interactions (Yoo et al., 2002). Based on these observations, oligomerization of Nod1 seems to represent a key initial event allowing the induction of downstream proinflammatory signals. Therefore, it is a critical issue to define what is the natural trigger of Nod1 oligomerization. In parallel with the studies on the activation of Apaf-1, it is conceivable that oligomerization of Nod1 is preceded by sensing of a specific ligand through the C-terminal LRR domain; indeed, Apaf-1 detects cytochrome $\mathrm{C}$ through its C-terminal WD repeat domain, allowing unfolding of the molecule and oligomerization (Adrain and Martin 2001). Recently, we have shown that infection of epithelial cells with the invasive bacteria Shigella flexneri is sufficient to induce oligomerization of Nod1 and subsequent activation of the NF-KB pathway through the recruitment of Rip2 and the IKK complex (Girardin et al., 2001). This observation suggests that Nod1 is able to detect a bacterial motif brought into the cytosolic compartment following the entry of S. flexneri into epithelial cells. Moreover, several reports have shown that commercial preparations of LPS can efficiently stimulate Nod1-dependent activation of both the NF-kB pathway and Caspase-1 (Inohara et al., 2001; Yoo et al., 2002). However, concluding that Nod1 is an intrac- 
ellular sensor of LPS is probably premature; indeed, Nod2 is also able to detect commercial preparations of LPS, but three recent reports have shown that this sensing was likely due to contamination of LPS preparations with a peptidoglycan motif, muramyl dipeptide (Chamaillard et al., 2003a; Girardin et al., 2003b; Inohara et al., 2003; see also below).

More recently, our laboratory and that of Dr Naohiro Inohara has uncovered the bacterial ligand sensed by Nod1 (Girardin et al., 2003a; Chamaillard et al., 2003b). Strikingly, Nod1 also senses a peptidoglycan motif but unlike Nod2, the motif sensed by Nod1 is found mainly in the peptidoglycan from Gram-negative bacteria. The naturally occurring peptidoglycan motif is comprised of $N$ acetylglucosamine- $N$-acetylmuramic acid substituted with a tripepetide group where the terminal amino acid is a meso-diaminopimelate (meso-DAP; Girardin et al., 2003a). Most Gram-positive organisms have a lysine residue in this position in their peptidoglycan structure and this motif is not recognized by Nod1. Furthermore, using synthetic components, Dr Inohara's group showed that $\gamma$ D-glutamyl-mesoDAP is sufficient for Nod1 activation indicating that this is the minimal structure recognized by Nod1 (Chamaillard et al., 2003b). Therefore, it is likely that meso-DAP containing peptidoglycan fragments contaminate commercial LPS preparations leading to the activation of Nod1. Taken together, these studies point to the conclusion that Nod1 is indeed an intracellular PRM that triggers the activation of pro-inflammatory signalling pathways following detection of a peptidoglycan motif from Gram-negative bacteria. Our findings also demonstrate that Nod1 is the sole surveillance system in epithelial cells as Gram-positive bacteria are not detected in these cells. Moreover, epithelial cells isolated from mice deficient in Nod1 do not detect Gram-negative bacterial products introduced to the intracellular compartment (Girardin et al., 2003a). The implications of these findings suggest that at least in the basal state, epithelial cells, like those that line the intestinal tract, have only the Nod1-dependent Gram-negative bacterial sensing system, perhaps reflecting the fact that most pathogens that infect this site are indeed Gram-negative.

\section{Nod2}

Following the identification of Nod1, Nod2, a second Nod molecule predominantly expressed in cells of the myeloid lineage, was discovered. Nod2 shares significant homology with Nod1, but unlike Nod1, possesses two CARD domains at its N-terminal end (Ogura et al., 2001b; Fig. 1). The initial characterization of the signalling pathways triggered by Nod2 also revealed similarities with the pathways downstream of Nod1. Indeed, the Nod2 pathway is induced following oligomerization through the recruitment of the Rip2/IKK cascade, which leads to the activation of NF-кB (Ogura et al., 2001b). The initial studies carried out to identify the nature of the motif detected by Nod2 suggested that intracellular presentation of LPS could trigger the Nod2 pathway (Inohara et al., 2001). However, our group recently demonstrated that whereas commercial preparations of LPS stimulate Nod2, further purification of the LPS abolishes the effect, demonstrating that a bacterial contaminant present in such LPS preparations was responsible for the activation of Nod2 (Chamaillard et al., 2003a). We could then identify peptidoglycan as the active contaminant. Moreover, our group and that of Gabriel Nuñez further identified that a specific peptidoglycan motif, muramyl dipeptide (MDP), was the specific bacterial ligand that is able to activate Nod2 (Girardin et al., 2003b; Inohara et al., 2003). Because MDP has been known for decades for its adjuvant properties on macrophages (MDP is the active compound of the Freund's adjuvant; Ellouz et al., 1974), these observations strongly suggest that Nod2 is responsible for the immuno-modulatory function of this bacterial molecule.

Although Nod2 expression was first thought to be restricted to cells of the myeloid lineage, recent studies have demonstrated that Nod2 mRNA can be detected in other cell populations, such as epithelial cells (Gutierrez et al., 2002; Berrebi et al., 2003; Rosenstiel et al., 2003). More importantly, Nod2 expression can be induced in epithelial cells following stimulation with TNF $\alpha$ or IFN $\gamma$ (Gutierrez et al., 2002; Rosenstiel et al., 2003), a mechanism that may explain the overactivation of the Nod2mediated pathway in inflamed colonic tissues of Crohn's disease patients (Berrebi et al., 2003; Fig. 2). Therefore, inflammation might trigger the induction of Nod2 in cells such as the epithelial cells lining mucosal surfaces, which represent one of the first cell populations encountered by an invasive pathogen. Because Nod2 is able to sense the presence of Gram-negative or Gram-positive bacteria in the cytosolic compartment through the detection of MDP, the upregulation of Nod2 in these cells is therefore likely to contribute to the early innate immune defence against invasive bacterial pathogens (Fig. 2). Accordingly, Hisamatsu et al. (2003) recently uncovered a new function of Nod2 in intestinal epithelial cells. The authors have implicated Nod2 in the killing of Salmonella once these bacteria are inside epithelial cells.

Taken together, several lines of evidence clearly identify Nod2 as a new intracellular PRM involved in innate immune defence against bacteria, not only in macrophages but also in epithelial cells from inflamed mucosal surfaces. The fact that Nod2 has also been independently identified as the first susceptibility gene for Crohn's disease (Hugot et al., 2001; Ogura et al., 2001a; see below) suggests intriguing interconnections between bacterial sensing/killing and inflammatory diseases. 


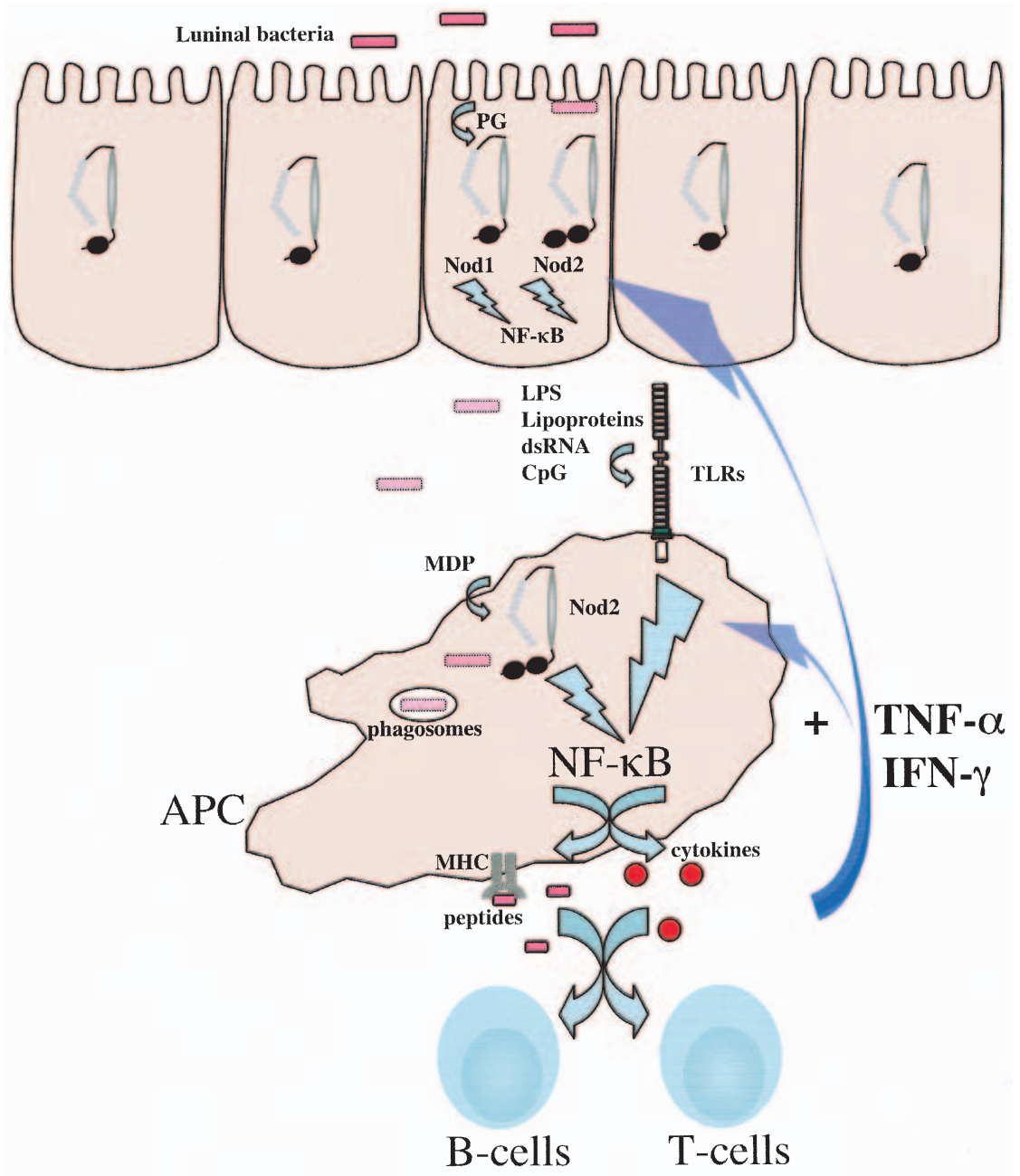

Fig. 2. Model for a role of Nod1 and Nod2 as cytosolic surveillance proteins of mucosal surfaces. Nod1 and Nod2 expressed by epithelial cells lining the intestinal surface and underlying macrophages maintain the mucosa in a basal state of inflammation. In conditions of bacterial infection and infiltration of the tissue, signals emanating for the epithelial surface via the activation of NF- $\mathrm{kB}$, as well as bacterial products present in the submucosa (like LPS, lipoproteins, PG and MDP) trigger underlying immune cells such as antigen-presenting cells (APC) to recruit the involvement of the adaptive immune system. Subsequent signalling by these cells, in the form of TNF $\alpha$ and IFN $\gamma$, upregulate Nod expression in the tissues in order to amplify the response.

\section{NALPS}

Nalps are NBS-LRR proteins that, instead of the CARD domain(s) found in Nod1 or Nod2, all contain a PYD domain at their N-terminal end (Fig. 1). Similar to the CARD domain of Nods, the PYD domain exclusively mediates PYD-PYD homophilic interactions (Bertin and DiStefano 2000; Martinon et al., 2001). Through genomic database search, Tschopp et al. (2003) have defined 14 Nalps in the human genome. Nalp2-14 all exhibit the following tripartite structure: PYD-NBS-LRR. Interestingly, an additional CARD domain is found at the C-terminal end of Nalp1. Moreover, ASC/PYCARD, an adaptor molecule containing an amino-terminal PYD domain and a carboxyterminal CARD domain, has been characterized (Srinivasula et al., 2002; Wang et al., 2002a). Therefore, Nalps can interact also with CARD containing molecules as has been shown for Ipaf (Masumoto et al., 2003), or CARDcontaining Caspases (Caspase-1 or Caspase-5) through this bipartite adaptor molecule. Indeed, Martinon et al.
(2002) have recently uncovered a key function of Nalps by showing that Nalp1 and ASC/PYCARD can form a molecular platform, termed the inflammasome, allowing the recruitment of Caspase- 1 and Caspase-5, followed by the activation of these pro-inflammatory caspases. Moreover, Nalp3 has been shown to form a complex involving ASC, Ipaf and Pyrin (Dowds et al., 2003; Masumoto et al., 2003).

The mechanism that triggers the formation of the inflammasome remains obscure. Because all Nalps contain an LRR domain, it is possible that Nalps are activated in a similar way as Nods through the LRR-dependent sensing of a specific molecular motif. Martinon et al. (2002) have observed that rupture of the cell integrity is sufficient to induce the formation of the inflammasome, suggesting that Nalps may be activated by a cellular component released after the destruction of cellular organelles. In this case, the activation of Nalps would represent a 'danger' response to major cellular damage, in a similar manner to that described for the activation of 
the Apaf-1 pathway by the release of cytochrome $c$ from the mitochondria (Adrain and Martin 2001). Alternatively, as all 14 Nalps each contain an LRR domain, it will be of interest to define if some Nalps could be activated through the detection of microbial patterns. This is a likely hypothesis since it has been shown that commercial preparations of LPS trigger the formation of the inflammasome in macrophages (Martinon et al., 2002). Whether this effect is mediated by LPS itself or by contaminants present in commercial LPS preparations remains to be defined.

\section{NBS-LRR proteins and genetic diseases}

A number of mammalian diseases have been shown to be linked with mutations in the genes encoding some of the NBS-LRR family members and associated proteins (Table 1). Remarkably, mutations in the genes encoding Nod2 and Nalp3 are together associated with five distinct genetic disorders characterized by aberrant inflammation (Ogura et al., 2001a; Hoffman et al., 2001; Hugot et al., 2001; Miceli-Richard et al., 2001; Aganna et al., 2002; Aksentijevich et al., 2002; Feldmann et al., 2002). Moreover, mutations in the genes encoding CIITA, Pyrin and Naip5 are associated with inflammatory disorders and susceptibility to bacterial infection (Steimle et al., 1993; The French FMF consortium, 1997; The international FMF consortium, 1997; Diez et al., 2003; Wright et al., 2003). These striking observations reveal the importance of this family in regulating the homeostasis of the immune system. We will restrict this discussion to Nod2-, Nalp3-, and Naip-associated diseases.

\section{Nod2 and predisposition to Crohn's disease}

Crohn's disease (CD) is a periodic and lifelong autoinflammation of the digestive tract associated with granuloma formation. Patients suffering from CD exhibit serious painful attacks of the gastrointestinal mucosa resulting in severe diarrhoea, bleeding, fever and malnutrition. The aetiology of CD remains unknown, although the pathological intestinal inflammatory response is thought to be a consequence of a breakdown of tolerance to bacterial flora in the gastrointestinal tract of genetically predisposed individuals (Podolsky 2002). Crohn's disease normally arises in the second or third decade of life and affects approximately one million Northern Americans and Western Europeans. Since the 1940s, the incidence of CD has dramatically increased in European-native and associated countries (Kurata et al., 1992) and more recently in populations of east Asian and African descent which have adopted a more 'westernized' lifestyle (Probert et al., 1993). These findings suggest the influence of a yet unknown environmental factor that favours the development of CD. On the other hand, similar to other known multifactorial disorders including multiple sclerosis and psoriasis, the rate of incidence of CD among monozygotic twins is approximately 10 fold higher than for dizygotic twins (Thompson et al., 1996; Orholm et al., 2000). Familial/ethnic aggregations (i.e. in Ashkenazi Jewish populations; Roth et al., 1989) and segregation studies (Kuster et al., 1989) also strongly suggest the influence of genetic factors in the aetiology of $\mathrm{CD}$, and more precisely the presence of recessive genetic determinants with incom-

Table 1. Human and animal diseases associated with mutations in NBS-LRR proteins.

\begin{tabular}{|c|c|c|c|}
\hline $\begin{array}{l}\text { NBS-LRR } \\
\text { protein }\end{array}$ & Other names & Associated diseases $^{a}$ & Predicted defect ${ }^{a}$ \\
\hline \multicolumn{4}{|l|}{ Nod subfamily } \\
\hline Nod2 & Card15 & $\begin{array}{l}\text { Crohn's disease } \\
\text { Blau syndrome }\end{array}$ & $\begin{array}{l}\text { Defective bacterial ligand sensing/other? } \\
\text { Constitutive (i.e. ligand-independent) } \\
\text { activation of NF-kB }\end{array}$ \\
\hline \multicolumn{4}{|l|}{ Nalp subfamily } \\
\hline Nalp3 & Pypaf1, CIAS1 Cryopyrin, & $\begin{array}{l}\text { Muckle-Wells syndrome (MWS) } \\
\text { Chronic infantile, neurologic, cutaneous, } \\
\text { articular syndrome (CINCA) } \\
\text { Familial cold auto-inflammatory } \\
\text { syndrome (FCAS) }\end{array}$ & $\begin{array}{l}\text { Ligand-independent activation of } \\
\text { caspase } 1 \text {; increased IL-1 } \beta \text { secretion } \\
\text { as above } \\
\text { Cold-triggered activation }\end{array}$ \\
\hline \multicolumn{4}{|l|}{ Ipaf subfamily } \\
\hline Naip & Birc1 & $\begin{array}{l}\text { Spinal muscular atrophy (Roy et al., } \\
\text { 1995) }\end{array}$ & $\begin{array}{l}\text { Failed caspase inhibition } \\
\text { (Liston et al., 1996). }\end{array}$ \\
\hline Naip5 (murine) & Birc1e & $\begin{array}{l}\text { Susceptibility to Legionella } \\
\text { pneumophila infection }\end{array}$ & as above or lack of bacterial sensing? \\
\hline \multicolumn{4}{|l|}{ CIITA subfamily } \\
\hline CIITA & $\begin{array}{l}\text { Bare lymphocyte syndrome } \\
\text { (Steimle et al., 1993) }\end{array}$ & & $\begin{array}{l}\text { Lack of MHCIl expression due to no } \\
\text { nuclear transolcation }\end{array}$ \\
\hline \multicolumn{4}{|c|}{ NBS-LRR-associated proteins } \\
\hline Pyrin & Marenostrin & Familial Mediterranean fever & $\begin{array}{l}\text { Defective bacterial ligand sensing and } \\
\text { apoptosis (Chae et al., 2003) }\end{array}$ \\
\hline
\end{tabular}

a. See text for references except for those indicated. 
plete penetrance. Finally, the influence of genetic variations is demonstrated from evidence of linkage studies in humans and in vivo dissection of targeted or spontaneous immune gene-deficient animals. Using a positional cloning strategy in out-bred European populations, three genetic variations of Nod2 have been independently associated with a predisposition to CD (Hugot et al., 2001). Following the alternate gene candidate approach, another group demonstrated independently the association between CD and one of these three Nod2 variants, the 1007-frame shift mutation. This frame-shift mutation, which predicts a truncated protein lacking the terminal LRR, is the most common form of Nod2 mutation associated with CD and acts as a loss-of-function mutation in the sensing of bacterial ligands (Ogura et al., 2001a).

More than $90 \%$ of the mutated alleles associated with $\mathrm{CD}$ affect the LRR region, suggesting a crucial role of this domain in the development of CD (Lesage et al., 2002). However, of the 32 distinct mutated alleles of Nod2 that have been studied, 13 show a defect in peptidoglycan sensing and/or an impairment in NF-кB activation. Of these, only four are in the LRR domain, including the most common Nod2 mutation associated with CD, the 1007 frame-shift mutation (Chamaillard et al., 2003a). Although these findings suggest that, in most cases of Nod2associated $C D$, impaired NF- $\mathrm{NB}$ activation by bacterial ligands is associated with disease (Fig. 3), factors other than those relating to NF- $\mathrm{KB}$ activation must be involved. Since Nod2 is also implicated in the activation of apoptosis (Ogura et al., 2001b) it is possible that dysregulation of apoptotic pathways due to mutations in Nod2 leads to aberrant inflammation.

\section{Gain of function mutations of Nod2 causing Blau syndrome}

Mutations in Nod2 have also been associated with Blau syndrome, a rare autosomal dominant disorder in which patients present with associated arthritis, uvetis, skin rashes and granuloma. Miceli-Richard and colleagues linked three mutations with this disease, implicating two distinct codons (R334Q-W and L469F) of the NBSassociated domain of Nod2 (Miceli-Richard et al., 2002). The two mutations at codon 334 were retrieved in five other distinct families (Wang et al., 2002b) supporting the hypothesis of a recurrent mutation. Surprisingly, the homologous position of this codon in the related NBSLRR protein Nalp3 (i.e. R260W) is also recurrently mutated in Muckle-Wells Syndrome (MWS) and familial cold autoinflammatory syndrome (FCAS) suggesting a common pathogenic mechanism of these structurally related proteins (Hoffman et al., 2001; Aganna et al., 2002; see below).

Constitutive NF- $\mathrm{KB}$ activation (i.e. independent of any exogenous stimulation) has been associated with the three reported mutations causing Blau syndrome (Chamaillard et al., 2003a; Fig. 3). Further studies are now required to confirm this observation for the dominant mutations in the Nalp3 gene (e.g. uncontrolled NF-KB and/ or apoptosis activation) and to document the physiological outcome of this stimulus-independent NF-KB activation (i.e. constitutive activation of Rip2, altered ATP binding, constitutive association to binding partners, turn-over, etc.).

\section{Nalp3 and autoinflammatory disorders}

The discovery of mutations in Nod2 associated with CD and Blau syndrome then provoked the screening of related NBS-LRR proteins in others inflammatory disorders. A Nalp subfamily member, Nalp3 (also known as Cryopyrin, Pypaf1 or Cias1; Manji et al., 2002), encoded by the cias 1 gene, has been recently associated with the expression of a broad phenotypic spectrum of dominantly inherited autoinflammatory disorders, including Muckle-Wells Syndrome (MWS), familial cold autoinflammatory syndrome (FCAS) (Hoffman et al., 2001; Aganna et al., 2002; Dode et al., 2002) and chronic neurologic cutaneous and articular syndrome (CINCA; Feldmann et al., 2002), also called NOMID (for neonatal onset multisystem inflammatory disease; Aksentijevich et al., 2002; see Fig. 3). All three of these disorders are characterized by recurrent inflammatory crises that are associated with fever, rash and arthritis. The major difference among these disorders is that, as suggested by the name, FCAS is precipitated by cold, whereas MWS and CINCA are chronic disorders with no specific trigger for the disease.

At least 22 distinct missense mutations, including 20 de novo mutational events, of the cias1 gene, encoding the Nalp3 protein, are associated with MWS, FCAS and CINCA (Aksentijevich et al., 2002). All of these mutations are within the NBS and NBS-associated domains. Notably, three mutations (V198M, D303N and R260W) are predisposing to the three syndromes suggesting the existence of modifying genes and/or environmental factors modulating the phenotypic expression. Knock-in and/or transgenic models with, for example, the R260W Nalp3 mutation, will help to investigate pathogenic mechanism and develop rational treatment for this disease.

\section{Naips: spinal muscular atrophy and susceptibility of mice to Legionella pneumophila infection}

Because of its sequence similarity to Ipaf in the NBS and LRR domains, Naip is included in this subfamily of NBSLRR proteins (Fig. 1; Tschopp et al., 2003). Ipaf, which contains an N-terminal CARD domain, is an activator of 


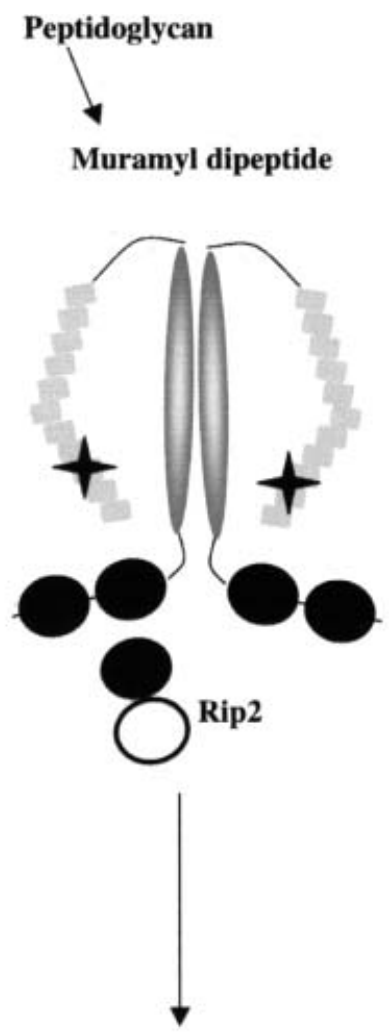

Loss-of-function

Failure

in NF-אB activation

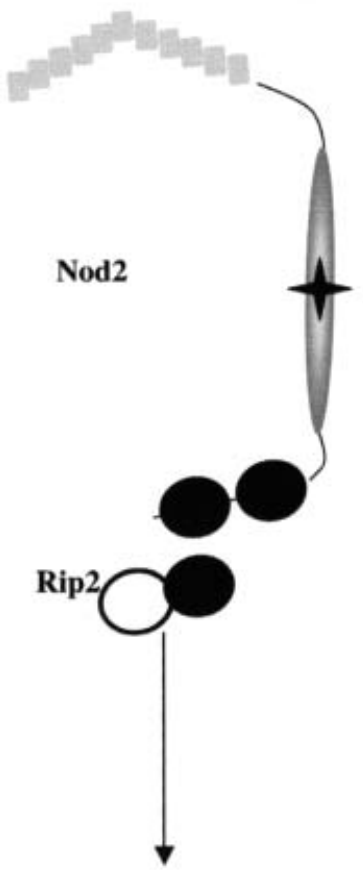

Dominant

Uncontrolled

NF- $\mathrm{KB}$ activation

Blau syndrome
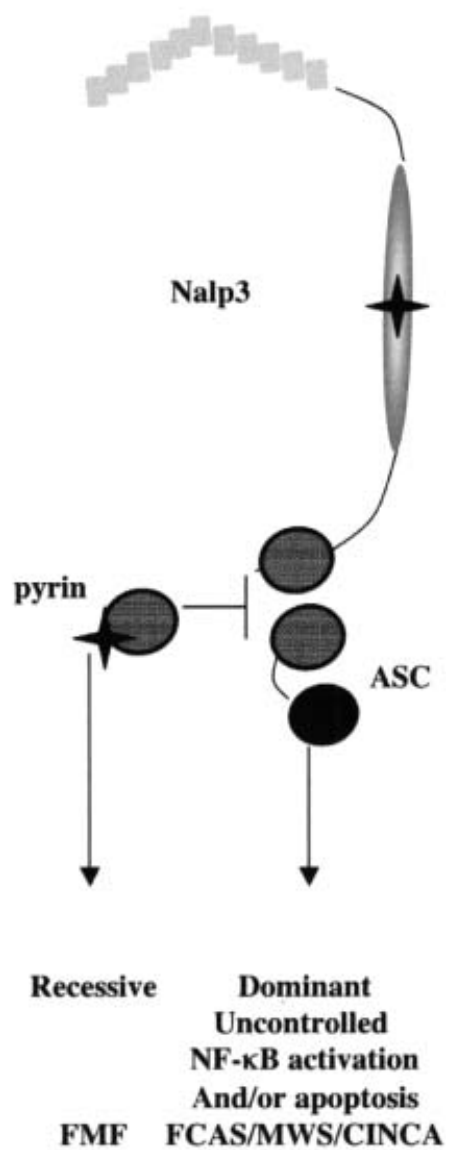

Kinase domain

Fig. 3. Possible mechanisms involved in human inflammatory diseases due to mutations in Nod2 and Nalp3. In the case of Crohn's disease, lack of muramyl dipeptide sensing due to mutations in the LRR domain of Nod2 prevent ligand triggered Rip2 association through homophilic CARD-CARD interactions and subsequent activation of NF-KB (Ogura et al., 2001; Girardin et al., 2003; Inohara et al., 2003). For Blau syndrome, mutations of Nod2 falling in the NBS region lead to constitutive activation of NF-kB and a constant stimulation of the inflammatory response (Chamaillard et al., 2003a). Pyrin, which is an adaptor likely involved in regulating Nalp3 activity by preventing ASC association (Dowds et al., 2003), is mutated in Familial Mediterranean Fever (FMF). This mutation likely results in amplified and unchecked Nalp3 activity. Mutations in the NBS-associated domain of Nalp3 are associated with three disorders: familial cold-autoinflammatory syndrome (FCAS), Muckle-Wells syndrome (MWS), and chronic infantile neurologic, cutaneous, articular syndrome (CINCA). These mutations likely lead to constitutive association of Nalp3 with its adaptor, ASC, leading to NF-KB, apoptosis and IL-1 $\beta$ generation (Srinivasula et al., 2002). 
caspase activity. In contrast, through its N-terminal BIR region, Naip inhibits effector caspases. In humans, mutations in Naip have been linked to the development of spinal muscular atrophy, which is a neurodegenerative disease characterized by progressive degeneration of lower motor neurons. Consistent with this phenotype, Naip appears to be mainly expressed in neurons where its role is to protect cells against apoptosis.

More recently, polymorphisms in mouse Naip5 have been associated with susceptibility to Legionella pneumophila infection (Diez et al., 2003; Wright et al., 2003). These findings stemmed from the observation that macrophages isolated from two different inbred strains of mice differ in their permissiveness to intracellular Legionella replication. In human macrophages, Legionella is capable of intracellular growth in specialized phagosomal compartments. However, in most inbred mice strains, isolated macrophages are non-permissive for Legionella replication. The one exception to this rule so far examined is the $\mathrm{A} / \mathrm{J}$ strain of mouse. In vitro, macrophages from these mice allow intracellular replication of Legionella. This phenotype difference segregates in Mendelian fashion and was shown to be controlled by the Lgn1 locus on chromosome 13. Using similar approaches, two groups identified the gene within this locus that is responsible for this phenotype as Naip5 (Diez et al., 2003; Wright et al., 2003). What is the possible mechanism by which Naip5 confers resistance to Legionella replication in mouse macrophages and what are the implications in human infection with this pathogen? So far, an association between apoptosis and Naip5-regulated Legionella replication has not been found (Diez et al., 2003; Wright et al., 2003). Therefore, it is plausible that Naip5 may be detecting a Legionellaspecific virulence factor that then triggers a yet unidentified antibacterial response in macrophages restricting the growth of this pathogen.

\section{Future prospects}

The recent characterization of the NBS-LRR family of intracellular proteins has allowed for the definition of a new paradigm connecting microbes and inflammation/inflammatory diseases. The originality of this emerging field of research certainly comes from the convergence of the disciplines of biochemistry and genetics. Indeed, using biochemical approaches, NBS-LRR proteins have been discovered as new intracellular sensors of bacterial patterns, such as Nod1, Nod2, and possibly Nalps. In parallel, a striking number of the genes encoding the NBSLRRs have been found associated with susceptibility loci for inflammatory disorders. The best example of such convergence is undoubtedly supported by the discovery that Nod2 functions as a sensor of MDP, and that Nod2 is the first identified susceptibility gene for Crohn's dis- ease. These studies provide a new support for the welldocumented hypothesis suggesting that inflammatory disorders such as IBD could be triggered by a breakdown of immune tolerance to commensal luminal flora. However, rather than assigning a definitive mechanistic explanation for the occurrence of these disorders, the characterization of the key role played by the NBS-LRR proteins in bacterial sensing and inflammation opens puzzling new questions.

An obvious central question arising from the studies on Nod2 is how are defects in bacterial sensing due to mutations in Nod2 associated with chronic inflammation and predisposition to Crohn's disease? Paradoxically, biochemical evidence suggests that bacterial sensing by PRMs from the innate immune system, such as TLRs and Nods, trigger the activation of pro-inflammatory pathways. Examples of such pro-inflammatory pathways include the activation of NF-kB, p38 and JNK, which leads to the expression of numerous cytokines and chemokines. Therefore, these observations are difficult to reconcile at the cellular level. Most probably, the right model will have to be defined at the level of the tissue, where homeostasis plays a central role. For instance, it can proposed that in normal conditions, a constant sampling of the microbial environment by cells of the mucosal surfaces (i.e epithelial cells or resident macrophages) leads to a physiological baseline level of inflammation. This constant immune surveillance provided by Nods, and possibly also TLRs, not only plays a role in steady-state basal conditions, but can also initiate a robust pro-inflammatory defence response following pathogenic stimuli. Therefore, the amplitude of inflammatory signals originating from mucosal surfaces is likely what defines the nature of the response driven by the adaptive immune system. Following this hypothesis, basal levels of inflammation stay below the threshold necessary to recruit cells of the adaptive immune system, whereas above this threshold, amplified inflammation drives involvement of this system (Fig. 2). Then, the characterization of defective bacterial sensing by mutated Nod2 associated with Crohn's disease leads to the following question: how does the adaptive immune system interpret the absence of a signal?

However, this failure to transduce bacterial-induced inflammatory signals (as exemplified by the $1007 \mathrm{fs}$ mutation in Nod2, the most common Nod2 mutation associated with $\mathrm{CD}$ ) is not a general feature of CD-associated Nod2 mutations. Indeed, by systematically analysing the ability of 32 individual CD-associated Nod2 mutations to transduce pro-inflammatory signals either in basal conditions or in response to peptidoglycan, Chamaillard et al. (2003a) have demonstrated the heterogeneity of the defects associated with Nod2 mutations towards bacterial sensing. Hence, $40 \%$ of CD-associated Nod 2 mutations lead to an inactive molecule, in either basal or peptidoglycan-stimulated conditions. Three mutants 
(R713C, E843K and 1007fs) display a Nod2 molecule still able transduce the NF-אB signal but which can no longer respond to peptidoglycan stimulation. For half of the other mutants, no defect in transducing the pro-inflammatory signal induced by peptidoglycan could be observed, indicating that Nod2 is also implicated in other cellular processes. Alternatively, these findings may suggest a high mutational rate, as observed in different strains of mice, that may be driven by positive selection (Ogura et al., 2003).

One such example of a newly described function for Nod2 is its direct antibacterial activity in intestinal epithelial cells (Hisamatsu et al., 2003). So far, the mechanism that allows these cells to kill intracellular Salmonella typhimurium remains unknown. A possible mechanism could involve the re-routing of the Salmonella phagocytic vacuole to lysosomes, as this phenomenon has been described in macrophages pretreated with MDP (Mukherjee et al., 2002), the bacterial molecule sensed by Nod2. It will be of interest to define if Nod2 displays a similar antibacterial activity on enteric invasive bacteria that escape their phagocytic vacuole such as Shigella flexneri.

Although the role of NBS-LRR proteins in innate immune defence remains largely unknown, recent progress has led to the characterization of some of the signalling pathways that they trigger. An important challenge is now to define what are the molecular motifs (microbial or from the host) that activate each individual member of this family. Moreover, it will be of importance to define if these NBS-LRRs directly interact with their activating agonists or if co-receptors are required to achieve sensing. Only then will we be able to understand how mutations of these NBS-LRR proteins can favour susceptibility to complex inflammatory diseases.

\section{Acknowledgements}

M.C. is supported by a grant from 'la Fondation pour la Recherche Medicale' and S.E.G. by a grant from Danone Vitapole, Paris. We thank Maria Mavris for her suggestions on the manuscript and Philippe Sansonetti for helpful discussion.

\section{References}

Adrain, C., and Martin, S.J. (2001) The mitochondrial apoptosome: a killer unleashed by the cytochrome seas. Trends Biochem Sci 26: 390-397.

Aganna, E., Martinon, F., Hawkins, P.N., Ross, J.B., Swan, D.C., Booth, D.R., et al. (2002) Association of mutations in the NALP3/CIAS1/PYPAF1 gene with a broad phenotype including recurrent fever, cold sensitivity, sensorineural deafness, and AA amyloidosis. Arthritis Rheum 46: 24452452.

Aksentijevich, I., Nowak, M., Mallah, M., Chae, J.J., Watford, W.T., Hofmann, S.R., et al. (2002) De novo CIAS1 mutations, cytokine activation, and evidence for genetic heterogeneity in patients with neonatal-onset multisystem inflammatory disease (NOMID): a new member of the expanding family of pyrin-associated autoinflammatory diseases. Arthritis Rheum 46: 3340-3348.

Barton, G.M., and Medzhitov, R. (2002) Toll-like receptors and their ligands. Curr Top Microbiol Immunol 270: 81-92.

Berrebi, D., Maudinas, R., Hugot, J.P., Chamaillard, M., Chareyre, F., De Lagausie, P., et al. (2003) Card15 gene overexpression in mononuclear and epithelial cells of the inflamed Crohn's disease colon. Gut 52: 840-846.

Bertin, J., and DiStefano, P.S. (2000) The PYRIN domain: a novel motif found in apoptosis and inflammation proteins. Cell Death Differ 7: 1273-1274.

Bertin, J., Nir, W.J., Fischer, C.M., Tayber, O.V., Errada, P.R., Grant, J.R., et al. (1999) Human CARD4 protein is a novel CED-4/Apaf-1 cell death family member that activates NFkappaB. J Biol Chem 274: 12955-12958.

Chae, J.J., Komarow, H.D., Cheng, J., Wood, G., Raben, N., Liu, P.P., and Kastner, D.L. (2003) Targeted disruption of Pyrin, the FMF protein, causes heightened sensitivity to endotoxin and a defect in macrophage apoptosis. Mol Cell 11: 591-604.

Chamaillard, M., Philpott, D., Girardin, S.E., Zouali, H., Lesage, S., Chareyre, F., et al. (2003a) Gene-environment interaction modulated by allelic heterogeneity in inflammatory diseases. Proc Natl Acad Sci USA 100: 3455-3460.

Chamaillard, M., Hashimoto, M., Horie, Y., Masumoto, J., Su, Q., Saab, L., et al. (2003b) An essential role for NOD1 in host recognition of bacterial peptidoglycan containing diaminopimelic acid. Nat Immunol 4: 702-707.

Diez, E., Lee, S.H., Gauthier, S., Yaraghi, Z., Tremblay, M., Vidal, S., and Gros, P. (2003) Birc1e is the gene within the Lgn1 locus associated with resistance to Legionella pneumophila. Nat Genet 33: 55-60.

Dode, C., Du Le, N., Cuisset, L., Letourneur, F., Berthelot, J.M., Vaudour, G., et al. (2002) New mutations of CIAS1 that are responsible for Muckle-Wells syndrome and familial cold urticaria: a novel mutation underlies both syndromes. Am J Hum Genet 70: 1498-1506.

Dowds, T.A., Masumoto, J., Chen, F.F., Ogura, Y., Inohara, N., and Nuñez, G. (2003) Regulation of cryopyrin/Pypaf1 signaling by pyrin, the familial Mediterranean fever gene product. Biochem Biophys Res Commun 302: 575-580.

Ellouz, F., Adam, A., Ciorbaru, R., and Lederer, E. (1974) Minimal structural requirements for adjuvant activity of bacterial peptidoglycan derivatives. Biochem Biophys Res Commun 59: 1317-1325.

Feldmann, J., Prieur, A.M., Quartier, P., Berquin, P., Cortis, E., Teillac-Hamel, D., and Fischer, A. (2002) Chronic infantile neurological cutaneous and articular syndrome is caused by mutations in CIAS1, a gene highly expressed in polymorphonuclear cells and chondrocytes. Am J Hum Genet 71: 198-203.

Girardin, S.E., Tournebize, R., Mavris, M., Page, A.L., Li, X., Stark, G.R., et al. (2001) CARD4/Nod1 mediates NFkappaB and JNK activation by invasive Shigella flexneri. EMBO Rep 2: 736-742.

Girardin, S.E., Sansonetti, P.J., and Philpott, D.J. (2002) Intracellular vs extracellular recognition of pathogens common concepts in mammals and flies. Trends Microbiol 10: 193-199.

Girardin, S.E., Boneca, I.G., Carneiro, L.A.M., Antignac, A., Jéhanno, M., Viala, J., et al. (2003a) Nod1 detects a unique muropeptide from Gram-negative bacterial peptidoglycan. Science 300: 1584-1587.

Girardin, S.E., Boneca, I.G., Viala, J., Chamaillard, M., 
Labigne, A., Thomas, G., Philpott, D.J., and Sansonetti, P.J. (2003b) Nod2 is a general sensor of peptidoglycan through muramyl dipeptide (MDP) detection. J Biol Chem 278: 8869-8872.

Gutierrez, O., Pipaon, C., Inohara, N., Fontalba, A., Ogura, Y., Prosper, F., Nuñez, G., and Fernandez-Luna, J.L. (2002) Induction of Nod2 in myelomonocytic and intestinal epithelial cells via nuclear factor-kappa B activation. J Biol Chem 277: 41701-41705.

Harton, J.A., Linhoff, M.W., Zhang, J., and Ting, J.P. (2002) CATERPILLER: a large family of mammalian genes containing CARD, pyrin, nucleotide-binding, and leucine-rich repeat domains. J Immunol 169: 4088-4093.

Hisamatsu, T., Suzuki, M., Reinecker, H.-C., Nadeau, W.J., McCormick, B.A., and Podolsky, D.K. (2003) CARD15/ NOD2 functions as an antibacterial factor in human intestinal epithelial cells. Gastroenterology 124: 993-1000.

Hoffman, H.M., Mueller, J.L., Broide, D.H., Wanderer, A.A., and Kolodner, R.D. (2001) Mutation of a new gene encoding a putative pyrin-like protein causes familial cold autoinflammatory syndrome and Muckle-Wells syndrome. Nat Genet 29: 301-305.

Hofmann, K., Bucher, P., and Tschopp, J. (1997) The CARD domain: a new apoptotic signalling motif. Trends Biochem Sci 22: 155-156.

Hugot, J.P., Chamaillard, M., Zouali, H., Lesage, S., Cezard, J.P., Belaiche, J., et al. (2001) Association of NOD2 leucine-rich repeat variants with susceptibility to Crohn's disease. Nature 411: 599-603.

Inohara, N., and Nuñez, G. (2003) Nods: intracellular proteins involved in inflammation and apoptosis. Nature Rev Immunol 3: 371-382.

Inohara, N., Koseki, T., del Peso, L., Hu, Y., Yee, C., Chen, S., et al. (1999) Nod1, an Apaf-1-like activator of caspase9 and nuclear factor-kappaB. J Biol Chem 274: 1456014567.

Inohara, N., Koseki, T., Lin, J., del Peso, L., Lucas, P.C., Chen, F.F., Ogura, Y., and Nuñez, G. (2000) An induced proximity model for NF-kappa B activation in the Nod1/ RICK and RIP signaling pathways. J Biol Chem 275: 27823-27831.

Inohara, N., Ogura, Y., Chen, F.F., Muto, A., and Nuñez, G. (2001) Human Nod1 confers responsiveness to bacterial lipopolysaccharides. J Biol Chem 276: 2551-2554.

Inohara, N., Ogura, Y., and Nuñez, G. (2002) Nods: a family of cytosolic proteins that regulate the host response to pathogens. Curr Opin Microbiol 5: 76-80.

Inohara, N., Ogura, Y., Fontalba, A., Gutierrez, O., Pons, F., Crespo, J., et al. (2003) Host recognition of bacterial muramyl dipeptide mediated through NOD2: implications for Crohn's disease. J Biol Chem 278: 5509-5512.

Kajava, A.V., and Kobe, B. (2002) Assessment of the ability to model proteins with leucine-rich repeats in light of the latest structural information. Protein Sci 11: 1082-1090.

Kobe, B., and Deisenhofer, J. (1993) Crystal structure of porcine ribonuclease inhibitor, a protein with leucine-rich repeats. Nature 366: 751-756.

Kobe, B., and Deisenhofer, J. (1994) The leucine-rich repeat: a versatile binding motif. Trends Biochem Sci 19: 415-421.

Kurata, J.H., Kantor-Fish, S., Frankl, H., Godby, P., and Vadheim, C.M. (1992) Crohn's disease among ethnic groups in a large health maintenance organization. Gastroenterology 102: 1940-1948.

Kuster, W., Pascoe, L., Purrmann, J., Funk, S., and Majew- ski, F. (1989) The genetics of Crohn disease: complex segregation analysis of a family study with 265 patients with Crohn disease and 5,387 relatives. Am J Med Genet 32: 105-108.

Lesage, S., Zouali, H., Cezard, J.P., Colombel, J.F., Belaiche, J., Almer, S., et al. (2002) CARD15/NOD2 mutational analysis and genotype-phenotype correlation in 612 patients with inflammatory bowel disease. Am $J$ Hum Genet 70: 845-857.

Linhoff, M.W., Harton, J.A., Cressman, D.E., Martin, B.K., and Ting, J.P. (2001) Two distinct domains within CIITA mediate self association: involvement of the GTP-binding and leucine-rich repeat domains. Mol Cell Biol 21: 30013011.

Liston, P., Roy, N., Tamai, K., Lefebvre, C., Baird, S., Cherton-Horvat, G., et al. (1996) Suppression of apoptosis in mammalian cells by NAIP and a related family of IAP genes. Nature 379: 349-353.

Manji, G.A., Wang, L., Geddes, B.J., Brown, M., Merriam, S., Al-Garawi, A., et al. (2002) PYPAF1, a PYRIN-containing Apaf1-like protein that assembles with ASC and regulates activation of NF-kappa B. J Biol Chem 277: 11570-11575.

Martinon, F., Hofmann, K., and Tschopp, J. (2001) The pyrin domain: a possible member of the death domain-fold family implicated in apoptosis and inflammation. Curr Biol 11: R118-R120.

Martinon, F., Burns, K., and Tschopp, J. (2002) The inflammasome: a molecular platform triggering activation of inflammatory caspases and processing of prolL-beta. Mol Cell 10: 417-426.

Masumoto, J., Dowds, T.A., Schaner, P., Chen, F.F., Ogura, Y., Li, M., et al. (2003) ASC is an activating adaptor for NFkappaB and caspase-8-dependent apoptosis. Biochem Biophys Res Commun 303: 69-73.

McCarthy, J.V., Ni, J., and Dixit, V.M. (1998) RIP2 is a novel NF-kappaB-activating and cell death-inducing kinase. $J$ Biol Chem 273: 16968-16975.

Medzhitov, R. (2001) Toll-like receptors and innate immunity. Nat Rev Immunol 1: 135-145.

Medzhitov, R., and Janeway, C.A. (1998) An ancient system of host defense. Curr Opin Immunol 10: 12-15.

Miceli-Richard, C., Lesage, S., Rybojad, M., Prieur, A.M., Manouvrier-Hanu, S., Hafner, R., et al. (2001) CARD15 mutations in Blau syndrome. Nat Genet 29: 19-20.

Mukherjee, K., Parashuraman, S., Krishnamurthy, G., Majumdar, J., Yadav, A., Kumar, R., Basu, S.K., and Mukhopadhyay, A. (2002) Diverting intracellular trafficking of Salmonella to the lysosome through activation of the late endocytic Rab7 by intracellular delivery of muramyl dipeptide. J Cell Sci 115: 3693-3701.

Nickerson, K., Sisk, T.J., Inohara, N., Yee, C.S., Kennell, J., Cho, M.C., Yannie, P.J., 2nd, Nuñez, G., and Chang, C.H. (2001) Dendritic cell-specific MHC class II transactivator contains a caspase recruitment domain that confers potent transactivation activity. J Biol Chem 276: 19089-19093.

Ogura, Y., Bonen, D.K., Inohara, N., Nicolae, D.L., Chen, F.F., Ramos, R., et al. (2001a) A frameshift mutation in NOD2 associated with susceptibility to Crohn's disease. Nature 411: 603-606.

Ogura, Y., Inohara, N., Benito, A., Chen, F.F., Yamaoka, S., and Nuñez, G. (2001b) Nod2, a Nod1/Apaf-1 family member that is restricted to monocytes and activates NFkappaB. J Biol Chem 276: 4812-4818.

Ogura, Y., Saab, L., Chen, F.F., Benito, A., Inohara, N., and 
Nuñez, G. (2003) Genetic variation and activity of mouse Nod2, a susceptibility gene for Crohn's disease. Genomics 81 (4): 369-377.

Orholm, M., Binder, V., Sorensen, T.I., Rasmussen, L.P., and Kyvik, K.O. (2000) Concordance of inflammatory bowel disease among Danish twins. Results of a nationwide study. Scand J Gastroenterol 35: 1075-1081.

Philpott, D.J., Girardin, S.E., and Sansonetti, P.S. (2001) Innate immune responses of epithelial cells following infection with bacterial pathogens. Curr Opin Immunol 13: 410-416.

Podolsky, D.K. (2002) Inflammatory bowel disease. N Engl J Med 347: 417-429.

Probert, C.S., Jayanthi, V., Hughes, A.O., Thompson, J.R., Wicks, A.C., and Mayberry, J.F. (1993) Prevalence and family risk of ulcerative colitis and Crohn's disease: an epidemiological study among Europeans and south Asians in Leicestershire. Gut 34: 1547-1551.

Rosenstiel, P., Fantini, M., Bräutigam, K., Kuhbacher, T., Waetzig, G., Seegert, D., and Schreiber, S. (2003) TNF-. and IFN- $\gamma$ regulate the expression of the NOD2 (CARD15) gene in human intestinal epithelial cells. Gastroenterology 124: 1001-1009.

Roth, M.P., Petersen, G.M., McElree, C., Feldman, E., and Rotter, J.I. (1989) Geographical origins of Jewish patients with inflammatory bowel disease. Gastroenterology 97: 900-904.

Roy, N., Mahadevan, M.S., McLean, M., Shutler, G., Yaraghi, Z., Farahani, R., et al. (1995) The gene for neuronal apoptosis inhibitory protein is partially deleted in individuals with spinal muscular atrophy. Cell 80: 167-178.

Schuster, J.M., and Nelson, P.S. (2000) Toll receptors: an expanding role in our understanding of human disease. $J$ Leukoc Biol 67: 767-773.

Srinivasula, S.M., Poyet, J.L., Razmara, M., Datta, P., Zhang, Z., and Alnemri, E.S. (2002) The PYRIN-CARD protein ASC is an activating adaptor for caspase-1. J Biol Chem 277: 21119-21122.

Staskawicz, B.J., Mudgett, M.B., Dangl, J.L., and Galan, J.E.
(2001) Common and contrasting themes of plant and animal diseases. Science 292: 2285-2289.

Steimle, V., Otten, L.A., Zufferey, M., and Mach, B. (1993) Complementation cloning of an $\mathrm{MHC}$ class II trans activator mutated in hereditary MHC class II deficiency (or bare lymphocyte syndrome). Cell 75: 135-146.

The French F.M.F. Consortium. (1997) A candidate gene for familial Mediterranean fever. Nat Genet 17: 25-31.

The International F.M.F. Consortium. (1997) Ancient missense mutations in a new member of the RoRet gene family are likely to cause familial Mediterranean fever. The International FMF Consortium. Cell 90: 797-807.

Thompson, N.P., Driscoll, R., Pounder, R.E., and Wakefield, A.J. (1996) Genetics versus environment in inflammatory bowel disease: results of a British twin study. BMJ 312: 95-96.

Tschopp, J., Martinon, F., and Burns, K. (2003) Nalps: a novel protein family involved in inflammation. Nat Rev Mol Cell Biol 4: 95-104.

Wang, L., Manji, G.A., Grenier, J.M., Al-Garawi, A., Merriam, S., Lora, J.M., et al. (2002a) PYPAF7, a novel PYRINcontaining Apaf1-like protein that regulates activation of NF-kappa B and caspase-1-dependent cytokine processing. J Biol Chem 277: 29874-29880.

Wang, X., Kuivaniemi, H., Bonavita, G., Mutkus, L., Mau, U., Blau, E., et al. (2002b) CARD15 mutations in familial granulomatosis syndromes: a study of the original Blau syndrome kindred and other families with large-vessel arteritis and cranial neuropathy. Arthritis Rheum 46: 3041-3045.

Wright, E.K., Goodart, S.A., Growney, J.D., Hadinoto, V., Endrizzi, M.G., Long, E.M., et al. (2003) Naip5 affects host susceptibility to the intracellular pathogen Legionella pneumophila. Curr Biol 13: 27-36.

Yoo, N.J., Park, W.S., Kim, S.Y., Reed, J.C., Son, S.G., Lee, J.Y., and Lee, S.H. (2002) Nod1, a CARD protein, enhances pro-interleukin-1beta processing through the interaction with pro-caspase-1. Biochem Biophys Res Commun 299: 652-658. 